\title{
Docentes de bachillerato en México. Su heterogeneidad y particularidad'
}

\author{
High School Teachers in Mexico. Their heterogeneity and particularity ${ }^{2}$
}

\section{Os professores do ensino médio no México. A sua heterogeneidade e particularidade ${ }^{3}$}

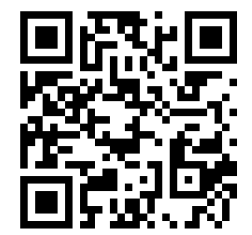

César Darío Fonseca-Bautista
Subsecretaría de Educación Media Superior
Unidad de Educación Media Superior Tecnológica Industrial y de Servicios
Centro de Bachillerato Tecnológico industrial y de servicios No. 76
Cuautla, México
cdfonseca19@yahoo.com.mx

http://orcid.org/0000-0001-5308-1295

Juan Manuel Piña-Osorio

Universidad Nacional Autónoma de México Instituto de Investigaciones Sobre la Universidad y la Educación

Ciudad de México, México jmpo@unam.mx

(D) http://orcid.org/0000-0003-4829-2260

Luz Marina Ibarra-Uribe

Universidad Autónoma del Estado de Morelos Facultad de Estudios Superiores de Cuautla Cuautla, México marina.ibarra@uaem.mx http://orcid.org/0000-0002-0808-5518

María de Guadalupe Pérez-Aguilar Universidad Autónoma Benito Juárez de Oaxaca Bachillerato Especializado en Contaduría y Administración

Oaxaca, México

lupis_mpa@hotmail.com http://orcid.org/0000-0002-3314-1251

Recibido • Received • Recebido: 19 / 07 / 2018

Corregido • Revised • Revisado: 12 / 11 / 2019

Aceptado • Accepted • Aprovado: 14/ 02 / 2020

\begin{abstract}
${ }^{1}$ Esta investigación colectiva contó con financiamiento del Programa de Apoyo a Proyectos de Investigación e Innovación Tecnológica (PAPIIT) de la Dirección General de Asuntos del Personal Académico (DGAPA) de la Universidad Nacional Autónoma de México. Número de proyecto IN400617.

${ }^{2}$ This collective research was funded by the Program of Support for Research and Technological Innovation Projects (PAPIIT) of the General Directorate of Academic Personnel Affairs (DGAPA) of the National Autonomous University of Mexico. Project number IN400617.

${ }^{3}$ Esta pesquisa coletiva foi financiada pelo Programa de Apoio a Projetos de Pesquisa e Inovação Tecnológica (PAPIIT) da Direção Geral de Assuntos Acadêmicos de Pessoal (DGAPA) da Universidade Nacional Autônoma do México. Número do projeto IN400617.
\end{abstract}


http://doi.org/10.15359/ree.24-2.7

ROR: https://ror.org/01t466c14 Universidad Nacional, Costa Rica

http://www.una.ac.cr/educare

educare@una.cr

Resumen: Este artículo analiza la heterogeneidad y particularidad del personal docente de educación media superior en México. Nuestro supuesto considera que la heterogeneidad se distribuye desigualmente. Seleccionamos y entrevistamos a 24 docentes de tres bachilleratos de subsistemas y regiones diferentes. El enfoque fue mixto, y la información se analizó a partir de cuatro ejes: ingreso a la docencia, perfil del profesorado, condiciones laborales y salariales, y participación sindical. En los resultados, encontramos tres espacios particulares, cada uno con su propia cultura escolar. En una institución, el ingreso para laborar es mediante examen de conocimiento, en otra por concurso de oposición y en la tercera mediante la influencia y recomendación de algún grupo de poder al interior de la institución. En dos planteles, las maestras y maestros imparten la materia que requiere la institución y en otro, la asignatura para la cual concursaron. Esto es importante advertirlo dada la heterogeneidad y diversidad de este profesorado, de cara a las políticas educativas, las cuales tienden a estandarizar sus evaluaciones; queda en evidencia la falta de correspondencia entre la política educativa, la diversidad contextual y las características y dinámicas de cada subsistema. Ante un escenario institucional operativo y normativo tan fragmentado, debido a que la educación media superior la ofrecen 40 subsistemas diferentes, el consenso, la sensibilización y coordinación de esfuerzos por parte de la autoridad educativa resultan determinantes para que, sin renunciar a la riqueza que ofrece la diversidad, esta posea vasos comunicantes en los puntos estratégicos de la política educativa nacional.

Palabras claves: Docente; bachillerato; docencia; sindicato; evaluación.

Abstract: This paper aims to analyze the heterogeneity and particularity of high school teachers in Mexico. Our perspective is that the heterogeneity of high school subsystems is unevenly distributed. The sample comprised 24 teachers from three high schools belonging to different subsystems and geographical regions. Quantitative and qualitative information was obtained and analyzed from four axes: admission to teaching, teacher's profile, working and salary conditions, and union participation. The main findings include the identification of three particular school spaces with their own school culture. In one institution, working positions are obtained through a knowledge exam; in another institution, they have exams for public service; in a third one, they consider influences and recommendations from groups of power. In two schools, teachers lead whichever subjects the institution requires, while in only one, they teach the subject for which they presented the exam. The heterogeneity and diversity of teachers need to be noticed by the educational policies considering that they tend to standardize their evaluations, and this reveals the lack of coherence between the educational policy, the diversity of regional, political and cultural contexts and the dynamics of each educational subsystem. In view of such fragmented operational and regulatory, institutional scenario (considering the 40 high school education subsystems), consensus, awareness, and coordination efforts of the federal educational authority are decisive for them to have - without giving up diversity"communicating vessels" in strategic points of the national educational policy.

Keywords: Professors; high school; teaching; union; evaluation.

Resumo: Este artigo analisa a heterogeneidade e a particularidade da equipe de professores do ensino médio no México. Nossa suposição parte de que a heterogeneidade está desigualmente distribuída. Selecionamos e entrevistamos 24 professores de três escolas secundárias de diferentes 
subsistemas e regiões. A abordagem foi mista, e a informação foi analisada a partir de quatro eixos: entrada à educação, perfil do professor, condições de trabalho e salários e participação sindical. Nos resultados encontramos três espaços particulares, cada um com sua própria cultura escolar. Em uma instituição, a entrada ao trabalho educativo é por exame de conhecimento, em outra, por exame competitivo, e na terceira, pela influência e recomendação de algum grupo de poder dentro da instituição. Em dois lugares educativos, os professores ensinam a disciplina exigida pela instituição e em outro, a disciplina para a qual concursaram. Isto é importante notar dada a heterogeneidade e diversidade deste corpo docente, tendo em vista as políticas educativas, que tendem a uniformizar as suas avaliações; é evidente que existe uma falta de correspondência entre política educativa, diversidade contextual, características e dinâmicas de cada subsistema. Em um cenário institucional, operacional e regulamentar tão fragmentado, dado que o ensino médio é oferecido por 40 subsistemas diferentes, o consenso, a consciência e a coordenação de esforços por parte da autoridade educativa são fatores determinantes para que, sem renunciar à riqueza que a diversidade oferece, tenha canais de comunicação em pontos estratégicos da política educativa nacional.

Palavras-chave: Professor; ensino médio; educação; sindicato; avaliação.

\section{Introducción}

En México, a la fase previa al ingreso de la educación superior se le denomina bachillerato o educación media superior (EMS). El objetivo de este artículo es identificar la heterogeneidad y particularidad en la planta docente de tres de los 40 subsistemas existentes en el país. Los tres planteles seleccionados se ubican en diferentes contextos de México. Uno de ellos corresponde al subsistema del bachillerato tecnológico, ubicado en el estado de Morelos y los otros dos al bachillerato universitario, uno localizado en el estado de Oaxaca y otro en el Estado de México.

La exposición inicia con una caracterización del personal docente como particular, es decir profesoras y profesores vistos como protagonistas que desempeñan su labor dentro de un contexto específico que se traduce en condiciones particulares para cada profesional. Se continúa con un panorama general del personal docente de EMS en México; se destaca su escolaridad, antigüedad y tipo de contratación. A continuación, se expone la metodología diseñada para el trabajo de campo, la aplicación de instrumentos y la sistematización de la información recopilada. Posteriormente se presentan los resultados obtenidos en cada uno de los tres espacios escolares. Se destaca el ingreso a la profesión docente, tipo de contratación y algunas expresiones de la cultura institucional en cada espacio. Finalmente, se realiza el análisis y las conclusiones.

\section{La particularidad docente}

En las sociedades latinoamericanas, la diversidad contextual, histórica, económica y social pone a flote particularidades que hacen casi imposible establecer una generalización del oficio docente. Torres $(2004$, p. 3 ) indica que en el siglo XXI se ha pensado que "el docente deseado o 
el docente eficaz es caracterizado como un sujeto polivalente profesional competente, agente de cambio, practicante reflexivo, profesor investigador, intelectual crítico...." Para la autora, son atributos difíciles de alcanzar, porque no se analizan las características particulares de los sistemas educativos latinoamericanos, de cada subsistema, de las culturas escolares específicas, de los reglamentos y especialmente, las condiciones laborales y salariales del profesorado. No obstante, esta situación no es exclusiva de Latinoamérica, porque para Lang (2007, p. 103), en Francia, el personal docente de secundaria forma un mundo heterogéneo, en donde "se observa cierta unificación en torno de tres grupos: el de profesores con agregación (12.7\%), el de docentes con certificado (63.5\%) y el de profesores de liceos profesionales (16\%)."

En consecuencia, el profesorado está formado por diversos grupos internamente diferenciados. Son profesores o profesoras, pero también son particulares. Para Heller (1977, p. 19), las numerosas actividades humanas que se realizan día a día, "sólo son idénticas en un plano... abstracto", porque en el plano concreto se expresan particularidades. El gran mundo social es la generalidad y lo que opera en la vida diaria es el pequeño mundo, el mundo particular del desempeño docente, acotado a un contexto histórico, a un país, a una región, a un subsistema. Aún más, profesoras y profesores de un mismo subsistema educativo, ubicados en regiones diferentes, pueden distinguirse por la cultura institucional que en cada plantel se ha construido, el tipo de contratación, ingresos, prácticas, porque cada espacio es particular. Prácticas aceptadas en un plantel, en otro pueden ser inaceptables.

La EMS es heterogénea y con numerosas particularidades. Uno de sus rasgos es su precariedad (Zorrilla, 2010), la cual se refleja en los escasos recursos que se le asignan para su operación. Se encuentra integrada por numerosos subsistemas, con financiamiento diferenciado, con sus propios reglamentos y tipos de contratación de personal, y sin una identidad propia definida. El Instituto Nacional para la Evaluación de la Educación (INEE, 2015, 2018) documentó la diversidad laboral del profesorado de EMS en México. Un porcentaje importante es contratado por horas, otro tanto por medio o tres cuartos de tiempo y, los menos, por tiempo completo. Realidad innegable, no obstante, ¿esta variedad se distribuye equitativamente en todos los subsistemas de la EMS, o la distribución es diferenciada? Para Zorrilla (2010, p. 27), se encuentran: "instituciones muy desigualmente financiadas, equipadas y operadas académicamente. Algunas lo hacen desde la precariedad más solemne, mientras otras laboran con financiamientos muy holgados." Algunas cifras ilustran esto.

\section{Panorama del personal docente de educación media superior en México}

La EMS comprende dos niveles educativos: el bachillerato (así como los demás niveles equivalentes a este) y la educación profesional técnica (técnico profesional medio). Este tipo educativo en la modalidad escolarizada se cursa en tres años. En los diferentes subsistemas 
educativos existentes se prepara a la juventud para continuar su formación escolar en el tipo superior (estudios de técnico superior universitario o estudios de licenciatura) o, en el caso del profesional técnico, para su incorporación al mercado laboral.

En concordancia con los informes elaborados por el INEE $(2015,2018)$, a continuación, se presenta una numeralia que permite caracterizar algunos aspectos del profesorado que conforma la EMS (ver Tabla 1).

Tabla 1: Algunos datos sobre el panorama general del personal docente de EMS en México

Del total de docentes que laboran en México (1.5 millones), el $19 \%(292,484)$ se desempeña en la EMS

\begin{tabular}{|c|c|}
\hline Sexo & $\begin{array}{l}\text { Mujeres } 52.3 \% \\
\text { Hombres } 47.7 \%\end{array}$ \\
\hline $\begin{array}{l}\text { Sostenimiento de los } \\
\text { planteles en que laboran }\end{array}$ & $\begin{array}{l}\text { Federal } 17.6 \% \\
\text { Estatal } 37.5 \% \\
\text { Autónomo } 11 \% \\
\text { Privado } 33.9 \% \\
\text { *Planteles agrupados en } 40 \text { subsistemas que ofrecen el servicio de EMS en todo el país }\end{array}$ \\
\hline Rango de edad & $\begin{array}{l}35 \text { a } 49 \text { años } 43.8 \% \\
25 \text { a } 34 \text { años } 31.6 \% \\
50 \text { a más años } 21.8 \% \\
24 \text { o menos años } 2.8 \%\end{array}$ \\
\hline Último grado de estudio & $\begin{array}{l}\text { Doctorado graduado } 0.87 \% \\
\text { Doctorado incompleto } 0.54 \% \\
\text { Maestría graduado } 12.3 \% \\
\text { Maestría incompleto } 4.83 \% \\
\text { Especialidad graduado } 1.68 \% \\
\text { Especialidad incompleto } 0.93 \% \\
\text { Licenciatura titulado } 65.48 \% \\
\text { Licenciatura incompleto } 6.90 \% \\
\text { Técnico superior titulado } 2.13 \% \\
\text { Técnico superior incompleto } 0.52 \% \\
\text { Normal terminada } 1.56 \% \\
\text { Normal incompleta } 0.15 \% \\
\text { Media superior o menos } 2.10 \%\end{array}$ \\
\hline Tipo de contratación & $\begin{array}{l}\text { Contrato por horas } 56.4 \% \\
\text { Tiempo completo } 21.2 \% \\
\text { Medio tiempo } 11.2 \% \\
\text { Labora } 30 \text { horas } 10.3 \%\end{array}$ \\
\hline
\end{tabular}

Nota: Elaboración propia, con base en la información proporcionados por el INEE $(2015,2018)$. 
La reestructuración de la vida escolar que trajo consigo la Reforma Educativa de 2013, la cual incluye la controversial implementación de la Ley General del Servicio Profesional Docente (LGSPD) que establece la evaluación del personal docente de planteles federales y descentralizados de los niveles educativos obligatorios, mediante un examen de conocimientos que garantice su idoneidad para continuar desempeñándose frente a un grupo. Si una persona docente no se acredita en tres ocasiones, puede ser retirada de su puesto como profesor o profesora y se asigna a desempeñar tareas administrativas. Todavía, en 2019, continuaban las protestas y rechazos de una parte del magisterio (Cedillo, 2017; Cuevas, 2017a, b; Díaz Barriga, 2017; González et al., 2017; Mercado, 2017). Cabe aclarar que lo anterior aplica para el bachillerato tecnológico. Para el caso de los otros dos planteles, estos se regulan a partir de la normatividad interna de instituciones de educación superior autónomas.

La reforma mencionada influyó para que una gran cantidad de docentes adscritos y adscritas a planteles de EMS de sostenimiento federal, promovieran su jubilación o retiro del SEM antes de que la reforma entrara en vigor. Con esta nueva legislación, el ingreso, permanencia y promoción del personal docente del sistema educativo público federal estaría sujeto a procesos de evaluación. Con ello se canceló una práctica recurrente en el país -sustentada en un acuerdo sindical- denominada de usos y costumbres, que consistía en que cuando alguien se retiraba de su función docente o renunciaba a esta, podía ceder (o vender) su lugar (que no su plaza) dentro del plantel a un familiar o a quien recomendara. La Reforma combatió lo que denomina Navarro (2002) mecanismos informales de reclutamiento, e inició una acelerada jubilación de docentes y el ingreso de una cantidad considerable, a través de la aprobación de un examen de conocimientos.

En México, el salario que recibe el personal docente no es tan competitivo como los de otras profesiones, sin embargo, existen algunas ventajas para quienes pertenecen a dicho gremio. Para el INEE (2015, p. 77), "se pueden citar cuando menos tres: la protección del salario; la compatibilidad entre el trabajo docente y el hogar [particularmente para el caso de las mujeres], y la seguridad en el empleo y las prestaciones sociales". En un contexto donde el empleo es escaso, inestable y con una tendencia a su precarización, un atractivo de la profesión docente es la seguridad laboral, las prestaciones federales y, además, dependiendo de cada subsistema y región geográfica, llegan otros beneficios que pueden superar las percepciones de otras profesiones. Cada subsistema se mueve con lógicas de trabajo académico y laborales diferentes. Con respecto a las primeras, en la formación del personal docente de la EMS intervienen también los lineamientos de cada subsistema, por lo que la oferta varía de un caso a otro. Y, con las segundas, en cada subsistema se establecen sus propias formas y tipos de contratación docente. La indagación empírica proporcionó las evidencias para identificar esta situación. 


\section{Metodología}

\section{Universo de estudio}

El universo de estudio se conformó por tres bachilleratos públicos, uno de carácter federal adscrito a la Unidad de Educación Media Superior Tecnológica Industrial y de Servicios (UEMSTIS) en el estado de Morelos; los otros dos corresponden a la modalidad de bachillerato universitario, uno pertenece a la Universidad Autónoma Benito Juárez Oaxaca (UABJO) y otro a la Universidad Autónoma Chapingo (UACH), localizada en el Estado de México. La población seleccionada procede de los tres planteles con la siguiente distribución: 8 docentes del estado de Morelos (33.33\%), 9 de Oaxaca (37.50\%), y 7 del Estado de México (29.17\%). Algunos datos sobre el perfil de las profesoras y profesores que participaron en la investigación se concentran en la Tabla 2.

Tabla 2: Caracterización de la población participante en la investigación

\begin{tabular}{|c|c|}
\hline Sexo & $\begin{array}{l}\text { Mujeres } 45.83 \% \\
\text { Hombres } 54.17 \%\end{array}$ \\
\hline Rango de edad & $\begin{array}{l}30 \text { a } 39 \text { años } 50 \% \\
40 \text { a } 49 \text { años } 25 \% \\
50 \text { a } 59 \text { años } 12.5 \% \\
60 \text { a más años } 12.5 \%\end{array}$ \\
\hline Último grado académico & $\begin{array}{l}\text { Licenciatura } 66.67 \% \\
\text { Doctorado } 25 \% \\
\text { Maestría } 8.33 \%\end{array}$ \\
\hline Tipo de contratación & $\begin{array}{l}\text { Contrato por horas } 50 \% \\
\text { Tiempo completo } 45.83 \% \\
\text { Cuartos de tiempo } 4.17 \%\end{array}$ \\
\hline $\begin{array}{l}\text { Años de servicio como } \\
\text { docentes en el plantel donde } \\
\text { se realizó el trabajo de campo }\end{array}$ & $\begin{array}{l}1 \text { a } 10 \text { años } 66.66 \% \\
11 \text { a } 20 \text { años } 12.5 \% \\
21 \text { a } 30 \text { años } 8.34 \% \\
31 \text { o más años de servicio } 12.5 \%\end{array}$ \\
\hline $\begin{array}{l}\text { Adscripción laboral del } \\
\text { personal docente }\end{array}$ & $\begin{array}{l}\text { 79.17\% del profesorado labora en otra institución además del bachillerato en estudio } \\
20.83 \text { \% se desempeñan como docentes exclusivamente en esa institución }\end{array}$ \\
\hline $\begin{array}{l}\text { Desempeño en actividades } \\
\text { no docentes }\end{array}$ & $\begin{array}{l}33.33 \% \text { desarrolla actividades asociadas con su formación de origen } \\
66.67 \% \text { se dedica únicamente a la docencia }\end{array}$ \\
\hline Participación sindical & $\begin{array}{l}95.83 \% \text { forman parte de un sindicato } \\
4.17 \% \text { se autodenominan independientes }\end{array}$ \\
\hline $\begin{array}{l}\text { Posibilidad de disponer de } \\
\text { algún programa de estímulos }\end{array}$ & $\begin{array}{l}70.83 \% \text { no participan en ningún programa de estímulos } \\
29.17 \% \text { se benefician de algún programa de estímulos }\end{array}$ \\
\hline
\end{tabular}

Nota: Elaboración propia, con base en la información obtenida del perfil de la población entrevistada. 


\section{Instrumento}

Se diseñó y empleó un guion de entrevista semiestructurada, integrada por tres secciones. En la primera se incluyeron preguntas cerradas sobre datos generales: edad, sexo, estado civil, formación académica, adscripción laboral, tipo de contratación y turno. La segunda contenía 34 preguntas guía, separadas en tres grupos: identidad, campo de representación y actitud. Para la integración del referente empírico que se interpreta en este artículo, se utilizó información sin distingo del grupo de procedencia de las preguntas. En la tercera parte se colocaron interrogantes específicas en función de las particularidades de cada plantel.

\section{Procedimiento}

La selección de informantes fue por conveniencia, las entrevistas se acordaron por invitación a docentes que aceptaran participar. Las entrevistas tuvieron un rango de duración de 35 a 90 minutos y fueron grabadas en audio para su posterior transcripción y análisis. Las preguntas cerradas fueron sistematizadas a través del paquete estadístico Excel, lo que posibilitó la integración de una base de datos para calcular frecuencias y porcentajes sobre el perfil de los sujetos entrevistados. Para el análisis de las transcripciones se utilizó el programa Atlas Ti. Se ubicaron elementos referentes al contexto y condiciones laborales del personal docente, lo que permitió situar cuatro ejes de análisis: ingreso a la docencia (herencia familiar, invitación, contacto personal, circunstancial, tequio y concurso de oposición); perfil del profesorado (sexo, edad, escolaridad y antigüedad); condiciones laborales y salariales (tipo de contratación, salario y estímulos) y participación sindical.

La metodología integra técnicas cuantitativas y cualitativas para aproximarse a los distintos contextos. Esa base permite interpretar las particularidades presentes en cada población de docentes. Estas se discuten en los apartados subsecuentes.

\section{El plantel de Bachillerato Tecnológico Industrial}

\section{Ingreso a la docencia}

Este plantel se formó hace 42 años con profesionistas que recientemente egresaban, una parte con titulación, otra en proceso de concluir la carrera, otra más que no concluyó sus estudios y otra que no se tituló. Con el paso de los años se fueron incorporando familiares de las personas trabajadoras; pocos docentes llegaron por permuta, y también hubo profesionistas que amistades o personas conocidas recomendaban con la dirección:

... me invitó a colaborar en un plantel federal recién creado, después adquirí la plaza y me fui re-categorizando desde abajo hasta llegar a la plaza más alta del modelo. (Profesor de 60 años) 
Me invitaron a trabajar, a cubrir un interinato de ... un año cuatro meses aproximadamente en este plantel... hasta que ya me asignaron una plaza de 19 horas. (Profesor de 38 años)

También se dio el caso que, estudiantado egresado del plantel, posteriormente fuera afiliado a la institución, incluso un director reciente egresó de la primera generación formada en el plantel.

\section{Ingreso por sustitución de un familiar}

Una segunda etapa fue cuando familiares de personal se formaron como profesionistas e iniciaron un relevo generacional. Para ello se estableció un Acuerdo de Asamblea Sindical, respaldado por la dirección del plantel y por las autoridades centrales del subsistema, el cual estableció que quien se retirara, jubilara, renunciara o falleciera, su plaza se reasignaría de manera parcial: $50 \%$ del total de las horas para su familiar y el otro $50 \%$ para que la dirección cubriera las necesidades académicas: Yo ingresé a la institución por sustitución de un familiar (Profesora de 39 años). Otro caso: Llegué a la docencia por medio de las jubilaciones que se han dado y pues me tocó por suerte, yo creo gracias a que cubrí los requisitos y me dieron la oportunidad (Profesora de 54 años).

Posteriormente, se amplió esta prerrogativa a docentes sin familiares en línea directa y se aprobó que pudieran recomendar a un conocido para que ingresara al plantel. Así se institucionalizó, durante siete años, lo que se conoció como la "herencia de plazas". En esta etapa, ya solo ingresaron a laborar profesionistas titulados.

Uno de los momentos álgidos del relevo generacional se presentó a partir de 2008 con la entrada en vigor de la Reforma Integral de Educación Media Superior (RIEMS), debido a la mayor exigencia para la capacitación docente en contenidos pedagógicos, en el uso de las nuevas tecnologías y el aprendizaje del idioma inglés. La RIEMS demandó un perfil docente con una serie de competencias y habilidade ${ }^{4}$ que algunas personas docentes no lograron aprender y desarrollar y otras no quisieron hacerlo. Ello colocó a profesoras y profesores, cuyas materias desaparecieron del plan de estudios, en la disyuntiva de lo que se conoció como las tres erres: reciclarse, reubicarse o retirarse.

\footnotetext{
${ }^{4}$ El perfil docente prescrito en la Reforma Integral de la Educación Media Superior está conformado por ocho competencias. 1. Organiza su formación continua a lo largo de su trayectoria profesional; 2. Domina y estructura los saberes para facilitar experiencias de aprendizaje significativo; 3. Planifica los procesos de enseñanza y de aprendizaje atendiendo al enfoque por competencias, y los ubica en contextos disciplinares, curriculares y sociales amplios; 4 . Lleva a la práctica procesos de enseñanza y de aprendizaje de manera efectiva, creativa e innovadora a su contexto institucional; 5 . Evalúa los procesos de enseñanza y de aprendizaje con un enfoque formativo; 6 . Construye ambientes para el aprendizaje autónomo y colaborativo; 7. Contribuye a la generación de un ambiente que facilite el desarrollo sano e integral de los estudiantes, y 8. Participa en los proyectos de mejora continua de su escuela y apoya la gestión institucional (SEGOB, 2008, Capítulo I. Objeto y Definiciones, párr. 3, 6, 9, 12, 15, 18, 21, 24).
} 
Otro momento importante fue cuando, en el marco de la Reforma Educativa de 2013, las autoridades centrales bloquearon todo trámite de asignación de plazas que no fuera a través de concurso (examen de conocimientos). En el caso del plantel sujeto de la investigación, docentes con antigüedad laboral suficiente para optar por la jubilación decidieron acelerar dicho proceso ante el comunicado sindical de que agosto 2015, sería el límite para poder ejercer el derecho sindical de heredar la plaza. Ingresaron 20 familiares o personas conocidas (la quinta parte del total de la planta docente). Llegaron profesionistas sin experiencia en la docencia (esta fue una constante hasta la entrada en vigor de los concursos), desconocían el modelo educativo, una parte acababa de egresar de la licenciatura, cuyos perfiles no respondían a las necesidades de la institución y, sumado a lo anterior, a otra parte no le agradaba dedicarse profesionalmente a la docencia; sin embargo, predominó una respuesta patrimonialista no me gusta, pero la plaza me la heredó mi mamá y ni modo que la rechace (Profesor de 38 años). Actualmente solo puede ingresarse a laborar vía concurso.

Cuando yo ingresé al subsistema lo hice a través de un examen, porque se requería un psicólogo. (Profesora de 59 años)

Concursé y sorpresa: quedo en primer lugar a nivel estatal en Economía, yo no me la creía, la verdad es que no me la creía. (Profesora de 47 años)

\section{Rituales de ingreso y permanencia}

A lo largo de las cuatro décadas de existencia del plantel se han institucionalizado ciertas prácticas que marcan la diferencia entre el profesorado de reciente incorporación y el de mediana y mayor antigüedad. Sin importar la forma cómo se ingresó, todos atraviesan por ciertos ritos de paso. Por ejemplo, docentes que recientemente llegan se les programa de dos a tres materias, no pueden sugerir su horario, ni asignatura a impartir y menos aspirar a seleccionar un determinado grupo o gestionar espacios físicos de trabajo. Todos deben pagar lo que se denomina derecho de piso. Los grupos idóneos, como se les reconoce oficialmente a los docentes y las docentes que ingresan a partir de la Reforma de 2013, concursan por horas, en casos muy específicos podrán trabajar en la asignatura que "ganaron", por ejemplo, inglés, porque se imparte en todos los semestres, el resto está sujeto a los requerimientos y necesidades del plantel:

Yo fui el profesor que tuvo 60 alumnos... Sí, trabajo mucho, porque una realidad del prelado es que nos están contratando con sueldos a un tercio con lo que un docente tradicional recibe. (Profesora de 47 años)

Es interesante constatar cómo el personal docente idóneo durante su estancia en el plantel, se agrupa, se relaciona y trabaja entre sí, a su vez, una parte de docentes establece cierta distancia frente a este grupo e incluso se resalta la forma como se les identifica: 
... percibo una ligera competencia, ... al principio fue, a ver si es cierto que eres bueno, a ver te voy a meter toda la presión, pero cuando empiezan a ver que realmente eres disciplinado, ... la gente cambia. (Profesora de 47 años)

\section{Perfil del personal docente}

Actualmente la planta está conformada por 104 docentes, 57 (55\%) hombres y 47 (45\%) mujeres. 71 cuentan con licenciatura (70\%) como último grado de estudios, 21 con maestría (21\%) y solo dos tienen doctorado (2\%). Llama la atención que 7\% (7 docentes) posee bachillerato o profesional técnico como últimos estudios. No obstante, a partir de la Reforma Educativa 2013, las plazas laborales se someten a concurso abierto y en los últimos tres años han ingresado alrededor de 14 docentes (13\%), es poco el profesorado joven o recién egresado de educación superior que trabaja en el plantel. Paradójicamente, la plantilla docente es madura. Apenas $2 \%$ son profesoras y profesores cuya edad fluctúa entre los 20 y los 29 años. El $29 \%$ se encuentra ubicado entre los 30 y los 39 años; $26 \%$ tiene entre 40 y los 49 años, $32 \%$ se ubica entre los 50 y los 59 años y, finalmente $11 \%$ tiene 60 años o más.

En cuanto a la antigüedad en el servicio docente, $31 \%$ es el segmento más numeroso, ellos cuentan con una antigüedad de 6 a 10 años, 30\% acumula de 26 años en adelante, 18\% tiene apenas 5 años de servicio y finalmente, 20\% cuenta con una antigüedad que va de 11 a 25 años. Por los datos expuestos, podemos deducir que estamos ante una plantilla de personal docente experimentado. De los 104 docentes, solo dos pertenecen al Sistema Nacional de Investigadores (SNI) y al Sistema Estatal de Investigadores (SEI).

\section{Condiciones laborales y salariales}

Una fortaleza académica de un plantel es su personal graduado y con nombramiento de tiempo completo o 40 horas, porque bajo esta condición laboral, los docentes y las docentes pueden realizar vida colegiada en la institución o, por lo menos, no tienen que cumplir su docencia en dos o más planteles. En este Bachillerato, 31.7\% cuenta con nombramientos que oscilan entre las 34 y las 40 horas, aunque de estos, solo $14 \%$ son de tiempo completo de carrera. Del resto, $15 \%$ cuenta con nombramiento de 30 horas, de estos, 16\% tiene plazas de medio tiempo y $54 \%$ nombramiento por horas. Entre el profesorado de tiempo completo de carrera o con nombramiento de 40 horas, a pesar de que sus categorías son diversas y ello se refleja en el monto de su remuneración salarial, su tipo de nombramientos les permite contar con descarga académica, disfrutar de año sabático y aspirar a becas-estudio por comisión sindical para realizar estudios de posgrado.

En pleno proceso de evaluación al desempeño docente, el programa de estímulos, que anualmente permitía a docentes de tiempo completo o de tres cuartos de tiempo, 
alcanzar -previa evaluación- un pago económico excepcional para fortalecer su práctica y productividad, fue cancelado. Sin mediar comunicado alguno, se anuló el programa y se trasladaron esos recursos a aquel personal docente que, habiendo presentado su evaluación del desempeño docente, hubieran logrado un resultado sobresaliente, en cuyo caso el estímulo les queda asegurado por cuatro años consecutivos. Este cambio, sin duda, fue una medida de presión para que el personal docente aceptara ser evaluado en el marco de la LGSPD.

El subsistema federal de bachilleratos tecnológicos cuenta con un catálogo de más de 50 tipos de plazas laborales, las cuales responden a las diversas categorías y condiciones a las que puede acceder el personal. Las docentes y los docentes recién incorporados vía concurso - de dos años a la fecha- se contratan con plazas de baja remuneración económica, sin derecho a descarga académica y cuya cantidad de horas fluctúa entre las 19 y las 30.

\section{Participación en el sindicato}

El Sindicato Nacional de Trabajadores de la Educación (SNTE) detenta la titularidad del contrato colectivo de la totalidad de personal del plantel. Todo el personal queda afiliado a dicha organización a partir del momento que es dado de alta como trabajador al servicio de la Secretaría de Educación Pública y, en consecuencia, obligado a aceptar el descuento quincenal de la cuota sindical. Con la Reforma Educativa, el Estado recuperó la rectoría en el ingreso, permanencia y promoción en el servicio educativo y con ello en 2015, canceló la permisividad para la herencia o venta de plazas, con lo cual el sindicato dejó de ser una instancia relevante en la vida docente del plantel, salvo para interceder, intervenir o mediar entre problemas laborales, los cuales son más bien esporádicos.

\section{Bachillerato universitario de Oaxaca}

La UABJO atiende al 73\% de la población escolar de licenciatura y posgrado del estado de Oaxaca. Concentra la mayor demanda para el ingreso a los estudios del tipo superior Universidad Autónoma Benito Juárez de Oaxaca [UABJO] (2013). En el año 2017, la matrícula universitaria fue de 26481 estudiantes, de los cuales 6726 se encontraban cursando el tipo medio superior (UABJO, 2017b). La EMS que imparte la universidad se compone por la modalidad presencial y a distancia. La presencial está conformada por ocho escuelas preparatorias, una de ellas es la que se estudia en el presente trabajo. Este bachillerato se distingue por ser el único adscrito a una unidad académica del tipo superior, la Facultad de Contaduría y Administración (FCA). Para el ciclo escolar 2016-2017, concentró una matrícula total de 480 jóvenes, de los cuales 269 fueron mujeres $(56 \%)$ y 211 , hombres (44\%). 


\section{Perfil del profesorado}

La planta docente en este bachillerato es de 57 docentes, 31 mujeres (54.39\%) y 26 hombres (45.61\%). Por su rango etario, la mayoría tiene entre 30 y 39 años (43.86\%), seguidos del grupo de 40 a 49 años que concentra 29.82\%, en tercer lugar, está el de 50 a 59 años de edad con el $17.54 \%$, finalmente, con 60 años o más aparece el $8.77 \%$. Por tipo de contratación, el $96.49 \%$ de la planta docente tiene contrato por asignatura, su salario se paga por hora-clase. Por otra parte, el $3.51 \%$ es profesor o profesora de tiempo completo, y su percepción salarial responde a su categoría laboral y antigüedad. En 2013 se implementó una reforma curricular en las preparatorias de la UABJO. A partir de ese cambio se distinguen dos grupos: a) El de mayor antigüedad, cuya formación es en las áreas económico-administrativa y en ciencias sociales y humanidades y b) El integrado por docentes de nuevo ingreso, con escolaridad encaminada a las ciencias experimentales y a la comunicación, áreas que demanda el nuevo plan de estudios.

La instrumentación del nuevo plan no fue sencilla, porque el personal docente con mayor antigüedad no coincidía con este. Esta situación ha impedido la instauración de academias por área, bajo el amparo de la premisa que sostiene que, en la universidad pública existe libertad de cátedra, cada docente define los contenidos y la forma de desarrollarlos en su aula. El bachillerato se encuentra en renovación, dado que el modelo por competencias se ha ido implementando de forma paulatina, y con algunas limitaciones, como la escasa capacitación docente, o ausencia de espacios y equipo necesario para realizar prácticas en el área de ciencias experimentales. ${ }^{5}$

\section{Ingreso del personal docente}

El Estatuto del Personal Académico de la Universidad Autónoma Benito Juárez de Oaxaca (UABJO, 1991) señala que el ingreso como docente al bachillerato es a través de un concurso por oposición. No obstante, el profesorado entrevistado, a través de su experiencia personal reveló tres formas de ingreso. La primera opción, por cuestiones circunstanciales, dentro de los movimientos políticos de la universidad, mencionada por el personal docente de mayor antigüedad. Comenta un maestro:

...me hablaron, y me dijeron que, si quería dar clases en este bachillerato, porque estaban dando clases alumnos que iban en grados avanzados... que todavía no tenían ni experiencia, ni tenían un título que los avalara como tales. (Profesor de 66 años)

La segunda forma, la más citada entre los sujetos entrevistados, fue a través de un contacto en la administración o en la planta docente, sean amistades o familiares: Sinceramente, yo me integro aquí a la docencia por invitación de un amigo (Profesor de 48 años).

\footnotetext{
${ }^{5} \mathrm{Al}$ ser este un bachillerato que forma parte de una universidad pública autónoma, no queda obligada a ceñirse a los lineamientos de la RIEMS, ni a la Reforma Educativa 2013 promovida por la Secretaría de Educación Pública.
} 
La tercera es a través del tequio, término que procede del náhuatl tequitl, que alude al trabajo como tarea o faena que se realiza para pagar un tributo y que consiste en el trabajo para beneficio común, sin pago (Real Academia Española, 2018). En el ámbito de ingreso a la planta docente universitaria, el concepto adquiere otra connotación, porque se trata de hacer las veces de profesorado-adjunto del titular, que no recibe salario y que cubre la o las asignaturas del segundo. Debe hacer méritos y, posteriormente, podrá ingresar formalmente a la planta docente. El tequio regularmente se acuerda entre una persona docente que pertenece a alguna estructura universitaria de autoridad y puede proteger a algún o alguna profesionista con interés en incorporarse como docente. Proteger, en el sentido de responder ante la inconformidad que pudiera surgir por parte de otros profesores o profesoras:

...en 1994 trabaja un amigo en el sindicato, ... nos fuimos haciendo amistades yél empezaba también a dar clases, por invitación más que nada llegué a la universidad, me dijo si podría yo apoyarle, se le llama aquí tequio. (Profesor de 50 años)

\section{Condiciones laborales y salariales}

La forma de contratación del personal docente es mayoritariamente por asignatura. El ingreso salarial es acorde con el número de horas-clase impartidas, así como la categoría donde se ubique; estas son homologadas o no homologadas. La primera categoría con niveles $A$ y $B$, la segunda con niveles A, B y C. Según información de documentos universitarios (UABJO, 2017a), los salarios por hora-clase son los siguientes: homologados nivel $A, \$ 71.06(3.58$, dólar) y nivel B \$83.03 (4.15 dólar); no homologados nivel A, \$48.18 (2.40 dólar), nivel B \$50.24 (2.5 dólar) y nivel C \$53.59 (2.67 dólar).

La categoría de profesorado por asignatura no homologado es la más frecuente. El pago por hora-clase después de los primeros cinco años de antigüedad llega a ser nivel C. El personal docente entrevistado califica su percepción salarial como baja. Para lograr un incremento de horas o la recategorización, el procedimiento no responde a requerimientos académicos, sino a relaciones y participación en algún grupo político de la universidad. Aunado a los bajos salarios, el profesorado señala que, ante la falta de estímulos al desempeño docente, su principal fuente de ingresos es otro tipo de actividades laborales. Por tanto, solo destinan a la actividad docente las horas frente a grupo, sin la posibilidad de participar en otras actividades que el plantel promueve:

... más de mi consulta privada, eso me impide a mi participar en programas de la escuela que requieran tiempo, y que me van a hacer que yo pierda dinero en mi consultorio, que es lo que sostiene a mi familia. (Profesor de 66 años)

Las condiciones de contratación enlistadas repercuten directamente en la percepción salarial de la comunidad docente del bachillerato. Destaca el hecho de que las cuestiones políticas y sindicales universitarias atraviesan las condiciones labores descritas en este trabajo. La característica de un

14 César Darío Fonseca-Bautista, Juan Manuel Piña-Osorio, Luz Marina Ibarra-Uribe y María de Guadalupe Pérez-Aguilar

Los artículos de la Revista Electrónica Educare del Centro de Investigación y Docencia en Educación de la Universidad Nacional, Costa Rica, se comparten bajo términos de la Licencia Creative Commons: Reconocimiento, № Comercial, Sin Obra Derivada 3.0 Costa Rica. Las autorizaciones adicionales a las aquí delimitadas se pueden obtener en el correo: educare@una.cr cc 
bachillerato universitario implica su conexión estrecha entre los dos tipos que ofrece la institución, lo cual supondría la colaboración entre ambos. En el caso de este bachillerato, el personal docente declara una desvinculación entre la licenciatura y el tipo medio superior, con un dejo de exclusión en las oportunidades y apoyos que se ofrecen a este último.

\section{Participación sindical}

La planta docente se agrupa en tres sindicatos, y uno de estos grupos sindicales está subdividido en tres fracciones. Estas corrientes se encargan de postular las demandas de sus agremiados y agremiadas, pero se involucran de forma más contundente en la participación para elegir a las autoridades universitarias. Desde 1977 la comunidad universitaria formada por la población estudiantil, el profesorado y trabajadores administrativos y manuales a través de la emisión del voto uninominal, directo, libre y secreto, eligen a sus autoridades: Rectoría, Direcciones de Unidades Académicas, Consejos Técnicos y Consejo Universitario (UABJO, 2017a).

Esta manera de elegir a las autoridades universitarias provoca pugnas entre las distintas corrientes políticas y sindicales que rebasan el periodo electoral, y se traduce en conflictos administrativos cotidianos al interior de cada escuela, lo cual afecta a la comunidad estudiantil, planta docente, administrativa y manual. En el caso del personal docente, la repercusión directa de los conflictos políticos se observa en las desigualdades de condiciones y oportunidades laborales. Por ejemplo: la figura del director hace compromisos políticos (Profesor de 48 años). Otro problema es la dificultad para establecer actividades docentes colegiadas que favorezcan al estudiantado, porque aquí ha estado muy politizada la situación y estamos los maestros que pertenecemos a diferentes grupos políticos, y entonces eso no ha permitido que nos reunamos... (Profesor de 48 años).

Respecto a la desigualdad de condiciones laborales, el profesorado reportó que no en todos los casos se respeta la correspondencia de la asignatura impartida y el perfil docente, ya que estas determinaciones obedecen a cuestiones de preferencia por antigüedad o por pertenencia al grupo que ostenta el poder. Las condiciones políticas y sindicales imperantes en el bachillerato generan pocas oportunidades para la colaboración académica y limitan las posibilidades de mejorar el desempeño docente. Esta dinámica institucional se traduce en pocos o escasos apoyos para participar en actividades de actualización o formación docente dentro de la universidad. Pues no, no hay ninguno de hecho a nivel institucional (Profesor de 38 años). Esto propicia que el profesorado opte por buscar cómo solventar esa necesidad de formación y actualización con sus propios medios ${ }^{6}$. Otro sector del profesorado se inclina por mantener su práctica docente y enriquecerla con el desempeño laboral de su perfil profesional.

\footnotetext{
${ }^{6}$ La universidad debería generar los mecanismos para que los docentes y las docentes incursionen en procesos de actualización con el respaldo económico de la institución.
} 


\section{Preparatoria Agrícola de la Universidad Autónoma Chapingo}

\section{Ingreso y perfil del personal académico}

La Universidad Autónoma Chapingo (UACH), en el año 2017 tuvo una matrícula de 10 384 estudiantes, de la cual 42\% cursaba la EMS (4 403). La planta académica estaba integrada por 1159 docentes, $93.2 \%$ con nombramiento de tiempo completo y solo $2.6 \%$ correspondió a profesorado de asignatura. Del total, 910 son hombres (78.5\%) y 249 mujeres (21.5\%). Destaca el porcentaje de personal académico con estudios de posgrado: $73 \%$. Un porcentaje importante de esta planta académica ha madurado, $60 \%$ tiene 60 años o más, lo que señala que la jubilación de la planta académica se prolonga (Unidad de Planeación, Organización y Métodos [UPOM], 2017).

El Estatuto Universitario de la UACH (Universidad Autónoma Chapingo [UACH], 2018b) establece que para ingresar a laborar como docente de tiempo completo es requisito presentar un examen de oposición señalado en la convocatoria. Esto se reafirma en el artículo 20 del Contrato Colectivo de Trabajo (UACH, 2018a), donde se especifica que el ingreso del personal académico a la universidad, en todos sus niveles, será por concurso de oposición, previa convocatoria, de manera que es imposible que alguna autoridad pueda contratar a personal académico sin este requisito. La convocatoria se publica en diversos espacios de la universidad y se dirige a quienes reúnen los criterios académicos solicitados. Los exámenes son abiertos. Un maestro expresa: comienzan a decir en la universidad y fuera de ella: hay un examen de oposición en Chapingo (Profesor de 65 años).

Hay que agregar que se concursa por una plaza de tiempo completo y se impartirá básicamente la materia y el nivel para el que se concursó y ganó. El Estatuto Universitario (UACH, 2018b), en su artículo 121ํ-, dice: "Los profesores del personal académico permanente solo podrán impartir cursos a nivel igual o inferior al grado académico que poseen, excepto en casos especiales dictaminados por los cuerpos colegiados correspondientes" (p. 25). Para el examen de oposición se forma una comisión con docentes. El examen consta de varias pruebas: currículo, examen de conocimientos, crítica al programa de la asignatura por la que se concursa o un proyecto de investigación, según defina el Consejo Departamental, y la exposición de una clase ante un grupo de estudiantes. Estos últimos también examinan a los sujetos candidatos. El examen de oposición es una práctica venerada por los grupos académicos. Es notorio que los sujetos entrevistados recuerdan lo que vivieron cuando realizaron su examen, en especial, si fueron varias las personas concursantes y una sola ganadora:

La primera vez competí con quince y no quedé. Luego me volví a presentar, pero en el área de Ciencias Sociales y no pasé. Luego fue ésta ..., competí contra tres y los dos quedaron descalificados en el camino. Yo llegué solita al final. (Profesora de 44 años) 


\section{Condiciones laborales y salariales}

El contrato laboral y todas las prestaciones son las mismas para el profesorado de preparatoria, licenciatura o posgrado. Sin embargo, ya en la vida cotidiana escolar, quienes laboran en licenciatura y, en particular profesionales de agronomía, etiquetan a quienes ejercen la docencia en Preparatoria. La clasificación es entre los grupos de primera (de licenciatura) y los de segunda (los de preparatoria). En esta clasificación se descalifica al profesorado de EMS y es más marcada cuando es de las áreas humanísticas y sociales (Piña, 1998).

El artículo 124- del Estatuto de Personal Académico, apunta: "Será un derecho de los profesores del Personal Académico Permanente, disponer de periodos de actualización en cualquier Universidad o Centro de Investigación, acorde a los lineamientos universitarios establecidos para tal fin" (UACH, 2018b, p. 25). Esto ha permitido a un porcentaje importante realizar estudios de posgrado, así como emprender una carrera académica e ingresar al SNI. En 2017, 127 docentes de la institución (10.95\% del total), pertenecían a este sistema de reconocimiento nacional. Para el 2018, ingresaron 133 docentes. De estos grupos, el 73\% se concentró en cuatro Departamentos de Enseñanza: Fitotecnia con 22, Preparatoria Agrícola con 19, Centros Regionales con 18 y Zootecnia con 14 (Dirección General de Investigación y Posgrado, 2018). Cabe mencionar que Preparatoria Agrícola tuvo 19 personas académicas. Es necesario reconocer que estos profesores y profesoras son, dentro de la $\mathrm{UACH}$, quienes tienen mayor carga académica, como denominan a los grupos escolares. Cada semestre atienden a un total de entre 100 y 150 estudiantes. No obstante, algunas personas lograron ingresar al SNI.

El sueldo se calcula con base en la categoría laboral y esta, por el grado académico. Una persona doctoranda joven, ganadora del examen de oposición, obtiene automáticamente la categoría más alta C2. Además, el profesor o profesora solo podrá impartir la materia por la cual concursó. Si desea impartir una clase diferente, su caso se turnará al Consejo Departamental y una comisión académica analizará si posee los conocimientos para hacerlo. Los salarios están homologados con los de la Universidad Nacional Autónoma de México (UNAM) y el de otras universidades públicas del país. En la UACH, la percepción monetaria de un profesor o profesora de posgrado es similar al bachillerato. El ingreso real cambia con la antigüedad laboral, como también con los estímulos académicos por productividad. Además, quienes ingresan al SNI tienen un estímulo económico que va de los $\$ 5000$ a los $\$ 7000$ (250 a 350 dólares, aproximadamente), según el nivel alcanzado.

Los siete sujetos entrevistados señalaron que no abandonarían la UACH, porque esta les ha permitido desarrollarse profesionalmente. Veamos algunas respuestas:

No me interesa, no me interesa [trabajar] en una empresa, ni tampoco una cuestión política, no lo sé, pero creo que no. (Profesora de 46 años) 
No, no la dejaría. De hecho, me ofrecieron no hace mucho la dirección de una revista. ... En este momento no, pero creo que pudiera hacerlo a la par, pero no dejaría la docencia. (Profesora de 44 años)

Con base en lo expresado por el profesorado, su interés se centra en la docencia, pero también expresaron su deseo por impartir clases en licenciatura o posgrado, pero en la UACH.

\section{Participación sindical}

El sindicato se formó en 1982, como un sindicato independiente del Estado mexicano y de las autoridades universitarias. La afiliación del profesorado es de manera voluntaria. De los siete docentes que colaboraron en esta investigación, seis pertenecen al sindicato. Uno no lo está porque es Cátedra del Consejo Nacional de Ciencia y Tecnología (CONACyT) y no puede sindicalizarse. Su empleador es el organismo federal y no la universidad. Según un académico entrevistado, de 1200 profesores que están integrados a la universidad, afiliados de manera voluntaria, hay 1080 (Profesor de 65 años).

Hay una idea generalizada de que el sindicato no debe defender a los malos profesores y profesoras, pero sí luchar porque la mayoría tenga mejores ingresos y prestaciones. El profesorado sabe que el sindicato lo apoya cuando sufre alguna arbitrariedad administrativa o académica. Para el grupo académico entrevistado, la función del sindicato es principalmente la defensa de los derechos del profesorado y no para enmascarar fallas laborales, ni para participar en la construcción académica, a mí en eso no, no coincido me parece que está ahí para la defensa de los derechos (Profesor de 40 años).

\section{Análisis y conclusiones}

Nuestro objetivo en esta investigación fue indagar sobre la heterogeneidad y particularidad del bachillerato mexicano, específicamente, en tres planteles de educación media superior de México, ubicados en tres entidades federativas del país. Dos de estos pertenecen al subsistema universitario y el otro al bachillerato tecnológico. Se partió del supuesto de que la heterogeneidad se distribuye de manera desigual, en algunos subsistemas se cuenta con los recursos económicos necesarios para cumplir con las tareas académicas y, en otros, se encuentran limitaciones severas. Incluso, en los mismos subsistemas del bachillerato universitario, por ejemplo, se encuentra esa heterogeneidad. Esta diversidad en el tratamiento financiero, aunado a lo específico de los reglamentos y a las prácticas consagradas a lo largo del tiempo, construye una particularidad escolar. Los resultados de la investigación demuestran que este objetivo se cumplió. Veamos por qué.

En primer lugar, el proceso de reclutamiento a la docencia es distinto en cada plantel: en el Bachillerato Tecnológico Industrial, el Sindicato Nacional de Trabajadores de la Educación 
avalaba o apoyaba la contratación de personal docente, con base en usos y costumbres, por ejemplo, la herencia o venta de la plaza laboral. Esto cambió drásticamente después de 2015. Con la implantación de la LGSPD, el ingreso es mediante examen de conocimientos, el cual es diseñado, aplicado y calificado por el gobierno federal.

En el Bachillerato Universitario de Oaxaca el Estatuto del Personal Académico de 1991 indica que el ingreso como docente a alguna dependencia de la universidad será mediante concurso por oposición. Sin embargo, en la práctica operan otros usos y costumbres, según explicó el profesorado entrevistado, a saber: a) cuando se requieren profesores o profesoras para impartir un curso específico, la contratación es directa; b) la más mencionada fue por invitación de una persona conocida o un amistades; c) por tequio, o trabajo docente sin pago por tiempo indefinido.

En la Preparatoria Agrícola de la Universidad Autónoma Chapingo el ingreso a la docencia es a través de convocatoria abierta, donde se especifican los requisitos para realizar examen de oposición para impartir una asignatura o un área. El jurado se forma por una comisión propuesta por el Consejo Departamental. Sus integrantes se encargarán de revisar el currículo, el grado, la experiencia docente, el proyecto de investigación y una demostración didáctica frente a grupo.

Con respecto a las condiciones laborales, se registraron las siguientes particularidades:

En el Bachillerato Tecnológico, una tercera parte de su planta docente tiene nombramiento entre 34 y 40 horas, de esta, solo unos cuantos sujetos han alcanzado el contrato de tiempo completo. El 15\% cuenta con nombramiento de 30 horas, y el 54\% por signatura y pago por horas. Solo docentes de tiempo completo o de contrato por 40 horas tienen licencia y beca para realizar estudios de posgrado, año sabático o descarga académica. El contrato de quienes recién se incorporan vía concurso, es entre 19 y 30 horas. Este tipo de contrato por horas ha permitido a las autoridades adjudicarle al profesorado asignaturas distintas. El principio contractual es que el contrato es por horas, no por asignatura. La formación profesional se subsume a esta tarea administrativa.

En el Bachillerato Universitario solo el 3.5\% posee nombramiento de tiempo completo. Sus ingresos responden a su categoría laboral y a su antigüedad. Por el contrario, el contrato laboral del $96 \%$ de la planta docente es por asignatura y su salario por hora-clase. Para lograr un aumento en horas o para su re-categorización, el mecanismo es mediante vínculos con algún grupo político al interior de la institución. La mayor parte de los ingresos de sus docentes proviene de otras actividades laborales. A eso se agrega que no se tiene apoyo institucional para quien desee realizar estudios de posgrado.

En la Preparatoria Agrícola casi el 100\% de docentes tiene contrato de tiempo completo $y$, posterior a obtener la contratación laboral por tiempo indefinido, pueden realizar estudios de posgrado en una institución de educación superior y, también, disfrutar del año sabático. 
Su categoría laboral y su percepción económica dependen de su grado académico. Quienes ostentan el grado de doctor, automáticamente, adquieren la máxima categoría laboral.

Las organizaciones sindicales participan en los tres planteles, pero la particularidad también aparece porque lo hacen de manera distinta:

En el Bachillerato Tecnológico el Sindicato Nacional de Trabajadores de la Educación es el gremio laboral hegemónico en el país, por tanto, todo el personal (docente y administrativo) queda automáticamente afiliado a dicha organización a partir del momento que es dado de alta como personal al servicio de la Secretaría de Educación Pública. En consecuencia, se le impone quincenalmente la retención de su respectiva cuota sindical.

En el Bachillerato Universitario la planta del profesorado pertenece a alguno de los tres sindicatos. Si el sindicato, o alguna de sus fracciones controlan una escuela o facultad, entonces tiene el poder necesario para incorporar a sus amistades o colegas.

En la Preparatoria Agrícola el sindicato es independiente del Estado y de las autoridades universitarias. La afiliación de profesorado se realiza de manera voluntaria. Su función principal es defender a sus sujetos agremiados de alguna arbitrariedad cometida por las direcciones de su departamento, así como vigilar y registrar cualquier violación al contrato colectivo de trabajo. Ejemplo de estas es si el funcionariado le impide a un profesor o profesora utilizar el año sabático al que tiene derecho, o para la realización de estudios de posgrado.

Como se ha expuesto, cada espacio es particular por las condiciones laborales de su profesorado y por su cultura escolar, lo cual ha llevado a que en dos planteles se ponderen los estudios de posgrado. Los resultados permiten entender esto:

En el Bachillerato Tecnológico los cuerpos docentes cuentan 70\% con licenciatura, $21 \%$ maestría; $2 \%$ doctorado (23\% con posgrado). En el Bachillerato Universitario se cuenta $96 \%$ licenciatura con y $4 \%$ posgrado y en la Preparatoria Agrícola $26 \%$ tiene licenciatura, $45 \%$ maestría y $29 \%$ doctorado ( $74 \%$ con posgrado).

Con base en los datos anteriores, la Preparatoria Agrícola posee las condiciones más favorables para que su planta académica emprenda estudios de posgrado y, en segundo lugar, el Bachillerato Tecnológico.

La relación de docentes con base en el sexo es distinta en cada espacio escolar. Veamos lo siguiente:

- Bachillerato Tecnológico 104 docentes, 55\% hombres y $45 \%$ mujeres

- Bachillerato Universitario 56 docentes, 54\% mujeres y $46 \%$ hombres

- Preparatoria Agrícola 332 docentes, 69\% hombres y 32\% mujeres 
En el Bachillerato Universitario las mujeres superan ligeramente al número de hombres, mientras que en el Bachillerato Tecnológico dominan los hombres. No obstante, la mayor diferencia la tuvo la Preparatoria Agrícola, porque más de dos terceras partes la integran los hombres. Esto puede responder a que la agronomía se ha considerado una carrera masculina y se asume que el campo es para los varones.

Las políticas educativas nacionales se introdujeron en el Bachillerato Tecnológico y en la Preparatoria Agrícola, pero lo hicieron de manera distinta:

En el BachilleratoTecnológico, el Estado mexicano, sin importarlas severas críticas realizadas por especialistas y de la movilización magisterial, impuso la Reforma Educativa de 2013, la cual se instrumentó en 2015. Con esta, se expropió al SNTE de las funciones de administración, incorporación, permanencia y promoción del profesorado. Esto alteró radicalmente los usos y costumbres y fue creando una nueva conformación de la planta docente.

En la Preparatoria Agrícola la evaluación de la investigación vía el SNI ha sido adoptada por un sector de profesorado de bachillerato. Ser personal investigador nacional tiene un efecto seductor, porque se obtiene un ingreso económico extra, aunado al valor simbólico que representa esta membresía.

En el Bachillerato Universitario las fracciones sindicales y los grupos de poder han impedido el ingreso de las políticas nacionales.

Lo anterior demuestra la heterogeneidad diferenciada y la particularidad en cada espacio escolar. En la Preparatoria Agrícola las condiciones laborales del profesorado son buenas, incluso privilegiadas, porque está establecido en los reglamentos institucionales que toda persona docente puede realizar estudios de posgrado. Por parte del profesorado, esta universidad es la pista indicada para emprender una carrera en investigación. En el Bachillerato Tecnológico, las condiciones son aceptables, pero especialmente para la planta docente de tiempo completo y de 40 horas de contrato, quienes pueden disfrutar de año sabático y también de licencia para estudiar un posgrado. La aspiración del personal docente de asignatura será obtener una plaza de tiempo completo titular, o bien, las 40 horas. En el Bachillerato Universitario las condiciones son precarias, la mayoría está obligada a permanecer como profesor o profesora de asignatura y, quienes realizan tequio, esperarán alguna oportunidad para tener sus propias materias.

Sirva este espacio para señalar que el tequio aplicado al espacio educativo es una práctica nociva para el ingreso docente, por lo que para evitar este tipo de prácticas se requiere un proceso de ingreso transparente y que valore los perfiles más adecuados en función de elementos académicos y no de cuestiones de grupos de poder o sindicales. El profesorado no debe verse comprometido con un grupo que le ayudó a su ingreso.

La heterogeneidad encontrada en el personal docente de la EMS es una muestra de la compleja dificultad para alcanzar la pretendida homogenización con la que la política 
educativa busca atender y operar el servicio educativo. Sin embargo, se reconocen numerosas dudas sobre el bachillerato y sus docentes. Mencionemos algunas: ¿Cómo se realiza la práctica docente en diversos espacios particulares? ¿Es diferente la enseñanza de quien ingresó por examen de conocimientos, de quien lo hizo através de una amistad? ¿Qué métodos y técnicas de enseñanza instrumentan docentes miembros del SNI, y quiénes han cursado exclusivamente estudios de licenciatura? ¿Cómo trabajan los contenidos un profesor o profesora con posgrado y otra persona con licenciatura, como también entre docentes con 20 o más años de antigüedad y otro grupo con menos de cinco años? La respuesta a estas interrogantes serán producto de futuras investigaciones.

\section{Referencias}

Cedillo-Arias, L. (2017). Retos del INEE ante la evaluación docente. En A. Díaz Barriga (Coord.), Docencia y evaluación en la Reforma Educativa de 2017 (pp. 63- 266). UNAM, IISUE.

Cuevas, Y. (2017a). Los maestros de secundaria y su representación social de la Reforma Educativa. La pérdida del trabajo. En Á. Díaz-Barriga (Coord.), Docencia y evaluación. La Reforma Educativa de 2017 (pp. 558-664). UNAM, IISUE.

Cuevas, Y. (2017b). Representaciones sociales de un grupo de docentes de la Ciudad de México sobre la evaluación del desempeño docente. RASE Revista de Sociología de la Educación, 10(3), 486-501. https://doi.org/10.7203/RASE.10.3.9917

Díaz Barriga, Á. (2017). Introducción. En Á. Díaz-Barriga (Coord.), Docencia y evaluación. La Reforma Educativa de 2017 (pp. 14-61). UNAM, IISUE.

Dirección General de Investigación y Posgrado. (2018). Profesores investigadores vigentes en 2018 en el Sistema Nacional de Investigadores (SNI). http://dgip.chapingo.mx/profesores-en-elsni-vigentes/

González, R., R., Rivera, L. y Guerra, M. (2017). Anatomía de la reforma educativa. México: UPN, Horizontes Educativos. editorial.upnvirtual.edu.mx/index.php/.../1-pdf?download... anatomia...reforma-educativ...

Heller, A. (1977). Sociología de la vida cotidiana. Península.

Instituto Nacional para la Evaluación de la Educación (INEE). (2015). Los docentes en México. Informe 2015. Autor. https://www.inee.edu.mx/publicaciones/los-docentes-en-mexicoinforme-2015/

Instituto Nacional para la Evaluación de la Educación (INEE). (2018). La educación obligatoria en México. Informe 2018. Autor. https://www.inee.edu.mx/publicaciones/la-educacionobligatoria-en-mexico-informe-2018/ 
Lang, V. (2007). La construcción social de las identidades profesionales de los docentes en Francia. Enfoques históricos y sociológicos. En E. Tenti Fanfani (Coord.), El oficio docente: Vocación, trabajo y profesión en el siglo XXI (pp. 71-118). Siglo XXI.

Mercado, L. (2017). Profesión docente: Los maestros ante las nuevas regulaciones para valorar su desempeño. En A. Díaz Barriga (Coord.), Docencia y evaluación. La Reforma Educativa de 2017 (pp. 267-376). UNAM, IISUE.

Navarro, J. C. (2002). El docente latinoamericano: Carrera, incentivos y desempeño. En J.C. Navarro (Ed.), ¿Quiénes son los maestros? Carreras e incentivos docentes en América Latina (pp. 1-47). Washington, DC: Banco Interamericano de Desarrollo. https://publications.iadb. org/es/publicacion/14217/quienes-son-los-maestros-carreras-e-incentivos-docentes-enamerica-latina

Piña, J. M. (1998). La interpretación de la vida cotidiana escolar. Tradiciones y prácticas académicas. Plaza y Valdés.

Real Academia Española. (2018). Diccionario de la lengua española (23a ed.). Madrid: Autor. http:// dle.rae.es/srv/search? $\mathrm{m}=30 \& \mathrm{w}=$ tequio

Secretaría de Gobernación (SEGOB). (29 de octubre, 2008). Acuerdo número 447 por el que se establecen las competencias docentes para quienes impartan educación media superior en la modalidad escolarizada. Diario Oficial de la Federación. http://dof.gob.mx/nota detalle.php?codigo $=5066425 \&$ fecha $=29 / 10 / 2008$

Torres, R. M. (2004). Nuevo rol docente: ¿Qué modelo de formación, para qué modelo educativo? Revista Colombiana de Educación, 47, 1-19. http://dx.doi.org/10.17227/01203916.5512

Universidad Autónoma Benito Juárez de Oaxaca (UABJO). (1991). Estatuto del personal académico de la Universidad Autónoma "Benito Juárez" de Oaxaca. Autor. http://www.transparencia. uabjo.mx/obligaciones/uabjo/articulo-70/fraccion-1/70-1-14-estatuto-del-personalacademico-de-la-uabjo-2017.pdf

Universidad Autónoma Benito Juárez de Oaxaca (UABJO). (2013). Segundo informe de gestión y administración universitaria. Autor http://www.transparencia.uabjo.mx/obligaciones/ rectoria/articulo-70/fraccion-29/70-29-157-segundo-informe-2017.pdf

Universidad Autónoma Benito Juárez de Oaxaca (UABJO). (2017a). Plan Institucional de Desarrollo 2016-2020. Oaxaca: Autor. http://www.uabjo.mx/pid-2016-2020

Universidad Autónoma Benito Juárez de Oaxaca (UABJO). (2017b). Primer Informe de Acciones Universitarias. (Rector Eduardo Carlos Bautista Martínez). Autor. http://www.uabjo.mx/ media/1/2017/07/Primer-Informe-2016-2020.pdf 
Universidad Autónoma Chapingo. (UACH). (2018a). Contrato Colectivo UACH-STAUACH. Autor. http://dgadmon.chapingo.mx/rechu/relaciones-laborales/ccustaUACh/

Universidad Autónoma Chapingo (UACH). (2018b). Estatuto de la Universidad Autónoma Chapingo. Autor. http://upom.chapingo.mx/wp-content/uploads/2018/06/estatuto uach-.pdf

Unidad de Planeación, Organización y Métodos (UPOM). (2017). Anuario estadístico. UACH. https://chapingo.mx/upom/Descargas/ae/anuario 2017.pdf

Zorrilla, J. F. (2010). El bachillerato mexicano: Un sistema académicamente precario. Causas y consecuencias. UNAM, IISUE. www.acuedi.org/ddata/11393.pdf 